УДК 159.922

\title{
Исследование способов совдадания в связи с показателями саморегудяции подростков: возрастные и гендерные особенности
}

\author{
Екатерина Г. Денисова, Яна А. Быкова* \\ Донской государственный технический университет, г. Ростов-на-Дону, \\ Российская Федерация \\ *E-mail: yananbykova@yandex.ru \\ *ORCID ID: https://orcid.org/0000-0002-6485-4932
}

\begin{abstract}
Аннотация
В статье представлены результаты исслеАования способов совладания в Связи С показателями саморегуляции подростков с учетом возрастных и гендерных особенностей. Во ВвеАении Аается теоретический обзор феноменов совладающего поведения и саморегуляции. Научная новизна данной работы заключается в АОполнительной Аиффференциации поАросткового возраста, что позволяет более поАробно исследовать характер связей заявленных феноменов. В разделе «Методы» описаны методы исследования и процедура применения методик: опросник «Способы совладающего поведения» в аАаптации Т. ^. Крюковой, опросник «Стиль саморегуляции поведения» В. И. Моросанова, тест-опросник «Исследование волевой саморегуляции» А. В. Зверькова, Е. В. Эйдмана. Аано описание выборки: 166 человек в возрасте от 15 Ао 20 ^ет (137 Аевушек, 29 юношей). В разАеле «Результаты» представлены результаты сравнительного анализа способов совлаАания и саморегуляции в вылеленных подгруппах по полу и возрасту, а также анализ связи исследуемых переменных в разных возрастных полгруппах полростков. Установлено, что у юношей преобладает стиль саморегуляции «Гибкосты), они более настойчивы и Аемонстрируют большее самообладание. Аевушки чаще предпочитают поиск социальной подАержки, принятие ответственности и избегание. При этом, показатели указанных виАов копинга у Аевушек отличаются большей напряженностью. Также выявлены существенные различия в характере связей в различных возрастных группах. В ОбсужАении результатов проведен анализ полученных результатов в соответствии с уровнем их значимости, а также с Аанными современных исслеАОваний. В Заключении приведены выводы по результатам исслеАования, описаны перспективы и практическая значимость Аанного исследования.
\end{abstract}

\section{КАючевые слова}

Совладающее поведение, копинг, саморегуляция, подростки, возрастные и гендерные особенности, волевая саморегуляция 


\title{
Дия цитирования
}

Денисова Е.Г., Быкова Я.А. Исследование способов совладания в связи с показателями саморегуляции подростков: возрастные и гендерные особенности // Инновационная наука: психология, педагогика, дефектология. 2021. Т. 4, № 5. C. 60-78. doi: https://doi.org/10.23947/2658-7165-2021-4-5-60-78

\section{Coping strategies and self-regulation indicators of adolescents: age and gender differences}

\author{
Ekaterina G. Denisova, Yana A. Bykova* \\ Don State Technical University, Rostov-on-Don, Russian Federation \\ *E-mail: yananbykova@yandex.ru \\ *ORCID ID: https://orcid.org/0000-0002-6485-4932
}

\begin{abstract}
The article presents a study of coping strategies and self-regulation of adolescents from age and gender perspective. The Introduction provides a theoretical overview of coping behavior and self-regulation. The scientific novelty of this work lies in the additional differentiation of adolescence, which allows a more detailed study of the relationships between coping and self-regulation. The Methods section describes the main research methods and the procedure for applying the following psychological tests: "Methods of coping behavior" (T. L. Kryukova), "Style of self-regulation of behavior" (V. I. Morosanova), "Research of volitional self-regulation" (A. V. Zverkova, E. V. Eidman). The sample description: 166 people aged 15 to 20 years (137 girls, 29 boys). The Results section presents the comparative analysis of the coping methods and self-regulation in the subgroups by gender and age, as well as an analysis of the relationship between them in different age subgroups of adolescents. It was found that the style of self-regulation "Flexibility" prevails among young men; they are more persistent and demonstrate greater self-control. Girls are more likely to prefer seeking social support, accepting responsibility, and avoiding. The indicators of these types of coping among girls also differ by greater tension. In addition, significant differences were found in the relationships between coping strategies and self-regulation in different age groups. The Discussion section contains the analysis of the obtained results in accordance with the level of their significance, as well as with the data of contemporary research. The Conclusion summarizes the findings, describes the prospects and practical significance of this study.
\end{abstract}

\section{Keywords}

Coping behavior, coping, self-regulation, adolescents, age and gender differences, volitional self-regulation 
Инновационная наука: психология. педагогика. дефектология 2021 TOM 4 № 5

ВОЗРАСТНАЯ ПСИХОЛОГИЯ

62 
поведения. В этой связи исследователи подчеркивают особую родь копинга в подростковом возрасте, способствующих успешному преодолению трудных жизненных ситуаций и социальной адаптации в целом (Николаева и др., 2019).

Особенностью подросткового возраста можно считать тот факт, что именно в этот период происходит бурное развитие тех личностных качеств, которые помогут в формировании навыков самостоятельности при принятии решений, способности к ответственному поведению, к проектированию своего будущего, в том числе, формируется самосознание и ориентировка дичности на собственную оценку (Овчарова, 2020; Dias, 2017). Формирование этих качеств во многом определяются особенностями саморегуляции подростков (Папшева, 2013).

Саморегуляция является интегративной структурой, которая вкдючает в себя интеллектуальные, когнитивные, волевые, эмоциональные, нравственные, мотивационные сферы (Быкова, 2021). Понятие саморегуяяция раскрывается через вектор направленности действия на того, кто его производит. Другими словами, объектом контроля и регуляции в данном случае для дичности выступают не объекты внешней реальности или поведение другого, а собственные поступки и действия, а также внутренние репрезентации, эмоционадьные реакции, и другие присущие этой дичности психические явления (Моросанова, 2010). Значимость конструктивности этих, направленных на самого себя, действий в подростковом возрасте сложно переоценить (Жукова, Богоявленская, Артеменков, 2021; Нижегородцева, Тарасова, 2017).

Необходимо отметить, что современные исследования подтверждают важность учета половых раздичий при организации психологического сопровождения подростков (Бартош, Бартош, 2012; Крюкова, 2005; Панина, 2011; Фельдштейн, 2005; Филатова, 2009). Биологический пол и половая идентичность оказывают существенное вдияние на развитие личности подростка: происходит усиление полоролевых ориентаций и критическое осмысление половой идентичности, формируются половые идеалы, интенсивно осваиваются мужские и женские роли (Филатова, 2009). При этом, динамика возрастных изменений способов совладания и стилей саморегуляции, а также связь между ними остается мало изученной.

Цель исследования: изучение способов совладания и стилей саморегуляции в выделенных подгруппах по полу и возрасту, а также анализ характера связей исследуемых переменных в разных возрастных подгруппах подростков.

\section{Методы}

В исследовании приняли участие 166 человек в возрасте от 15 до 20 лет (137 девушек, 29 юношей), учащиеся средних образовательных и специальных образовательных учреждений г. Ростова-на-Дону и Ростовской области.

Для изучения заявленных показателей применялись следующие методы эмпирического исследования: 
ВОЗРАСТНАЯ ПСИХОЛОГИЯ

Психологическое тестирование: определения способов (копинг-механизмов, копинг-стратегий) преодоления трудностей в раздичных сферах - опросник «Способы совладающего поведения» (в адаптации Т. А. Крюковой); для практической диагностики раздичных аспектов индивидуальной саморегуляции опросник «Стиль саморегуляции поведения» (В. И. Моросанова); для определения уровня развития волевой саморегуляции - тест-опросник «Исследование волевой саморегуляции» (А. В. Зверьков и Е. В. Эйдман);

Методы математической статистики: критерий Шапиро-Уилка; непараметрический U-критерий Манна-Уитни; коэффициент ранговой корреляции Спирмена.

\section{Результаты}

С целью рассмотрения гендерного аспекта совладающего поведения и саморегуляции подростков был проведен сравнительный анадиз по исследуемым показателям в подгруппах юношей и девушек. Сравнительный анализ средних значений по способам совладания приведен на рисунке 1.

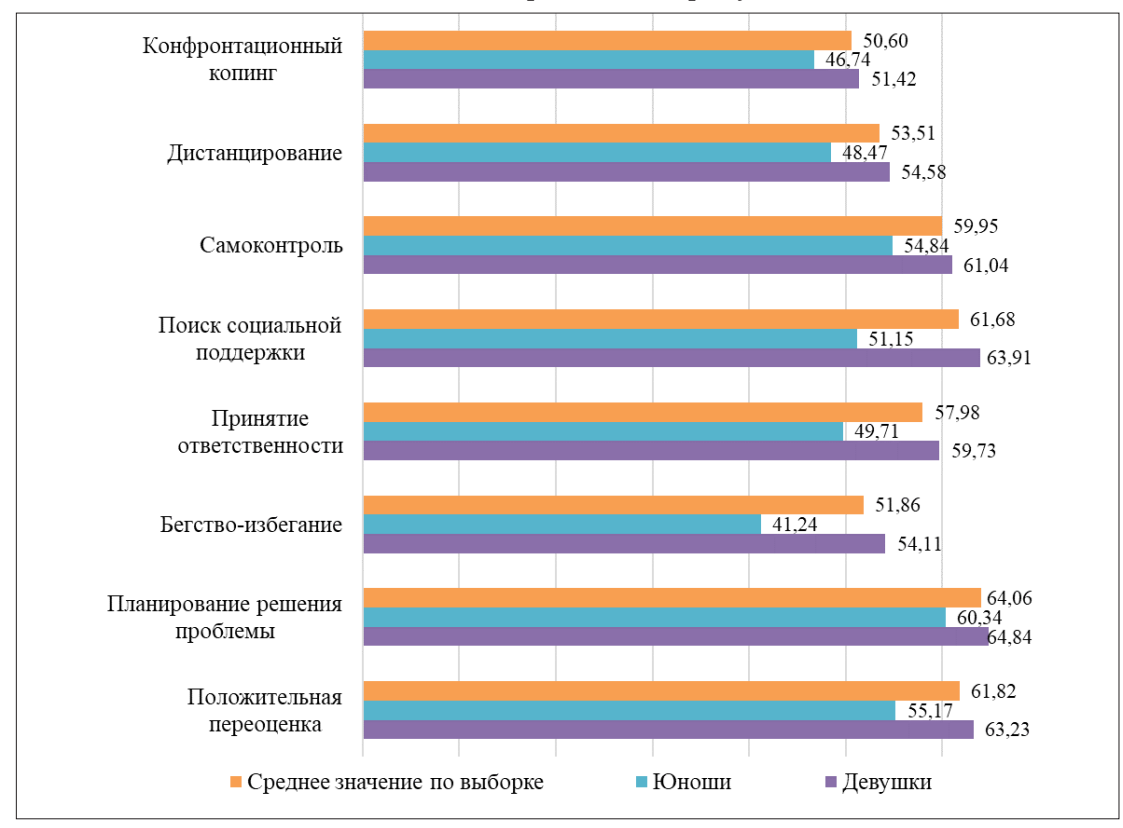

Рисунок 1. Средние значения показателей способов совладания (по полу).

Приведенные данные свидетельствуют о том, что в целом по выборке наиболее предпочитаемыми стратегиями совладания являются «планирование 
решения проблемы» (64,06 балла), «положительная переоценка» $(61,82$ балла) и «поиск социальной поддержки» (61,68 балла). В подгруппе девушек все перечисленные стратегии выражены примерно в равной степени, а вот в подгруппе юношей наиболее высокие значения отмечены по шкале «планирование решения проблемы». Средние значения по всем стратегиям совладания в подгруппе девушек отличаются более высокой напряженностью, что может быть индикатором риска дезадаптации. Данные статистического анадиза свидетельствуют о том, что достоверные раздичия отмечаются по шкалам способов совладания: «Поиск социальной поддержки» ( $<<0,002)$, «Принятие ответственности» $(\mathrm{p}<0,02)$, «Бегство-избегание» $(\mathrm{p}<0,003)$.

В целом, у девушек отмечен высокий уровень напряженности копинга таких показателей, как «поиск социальной поддержки», «принятие ответственности», «избегание», что свидетельствует о выраженной дезадаптации. У юношей преобладают средние показатели, это является признаком того, что у них выражен адаптационный потенциал личности в пограничном состоянии.

Сравнительный анализ средних значений по стилям саморегуляции приведен на рисунке 2.

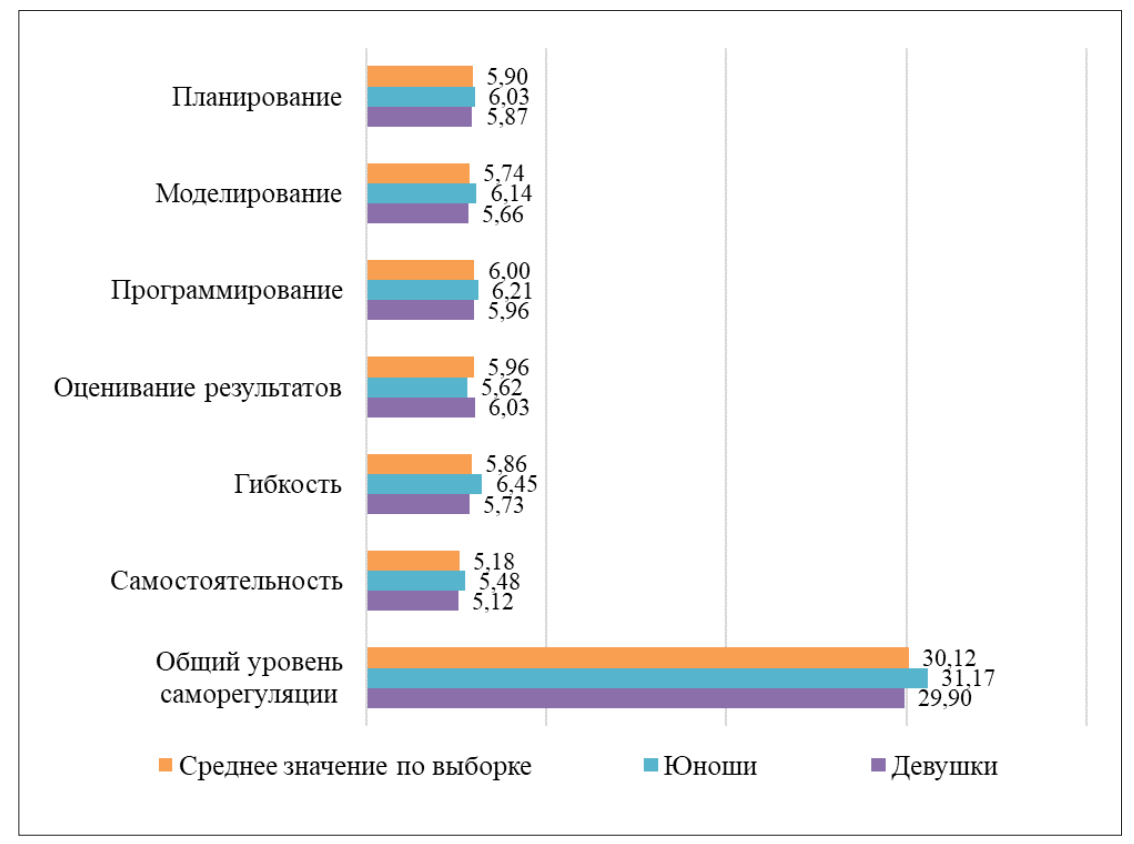

Рисунок 2. Средние значения показателей саморегуляции (по полу). 
ВОЗРАСТНАЯ ПСИХОЛОГИЯ

Данные свидетельствуют о том, что в целом по выборке преобладают такие стили саморегуляции как «программирование» (6 баллов), «оценивание результатов» (5,96 балла) и «гибкость» (5,86 балла). В подгруппе юношей значения по всем стилям саморегуляции поведения выше, в сравнении с девушками. Исключение составляет тодько параметр оценивание результатов. Однако данные статистического анадиза свидетельствуют о том, что достоверные раздичия отмечаются только по шкале «Гибкость» $(\mathrm{p}<0,02)$.

Сравнительный анализ средних значений по компонентам и уровню волевой саморегуляции приведен на рисунке 3.

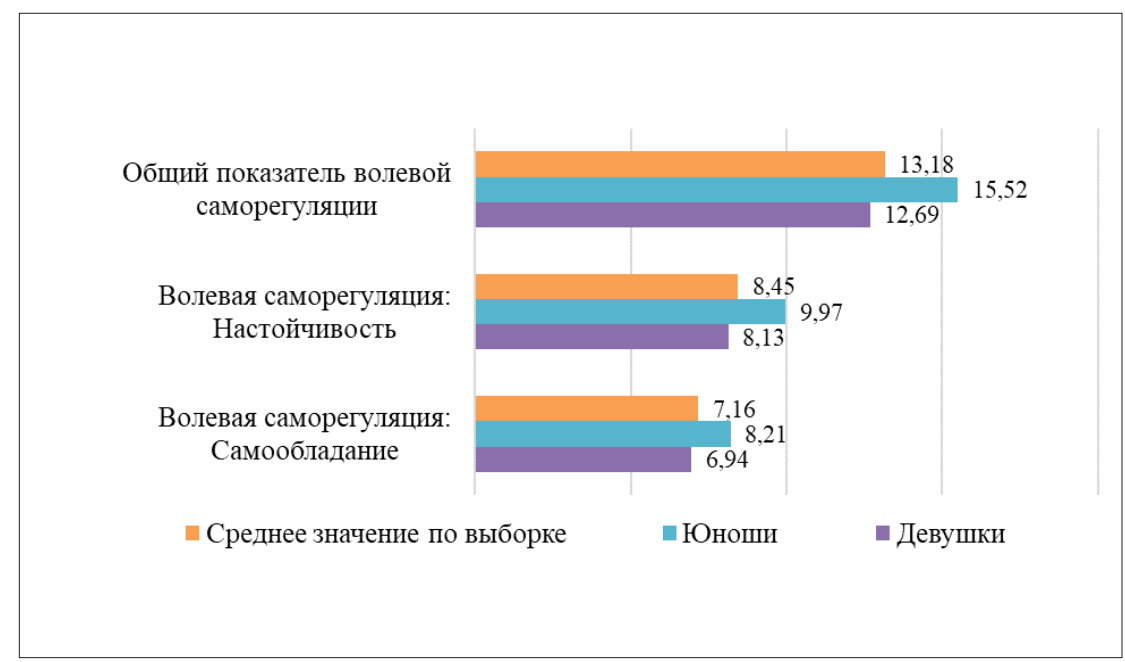

Рисунок 3. Средние значения показателей волевой саморегуляции (по полу).

По компонентам волевой регуляции, так же показано, что в подгруппе юношей значения выше, в сравнении с девушками. Общий уровень саморегуляции, и общий показатель волевой саморегуляции выше в подгруппе юношей. Статистический анализ свидетельствует о том, что достоверные раздичия отмечаются по всем шкалам опросника волевой саморегуляции: «Общий показатель волевой саморегуляции» $(\mathrm{p}<0,01)$, «Настойчивость» $(\mathrm{p}<0,03)$, «Самообладание» $(\mathrm{p}<0,01)$.

Так, по показателю саморегуляции установлено, что в подгруппе юношей достоверно преобладает стиль саморегуляции «Гибкость», они более настойчивы и демонстрируют самообладание. При этом, значения по выборке в целом не превышают нормативных значений по методикам, что свидетельствует о среднем уровне развития саморегуляции. 
Далее обратимся к результатам анадиза возрастной динамики совладания и саморегуляции. Сравнительный анализ средних значений способов совладания приведен на рисунке 4.

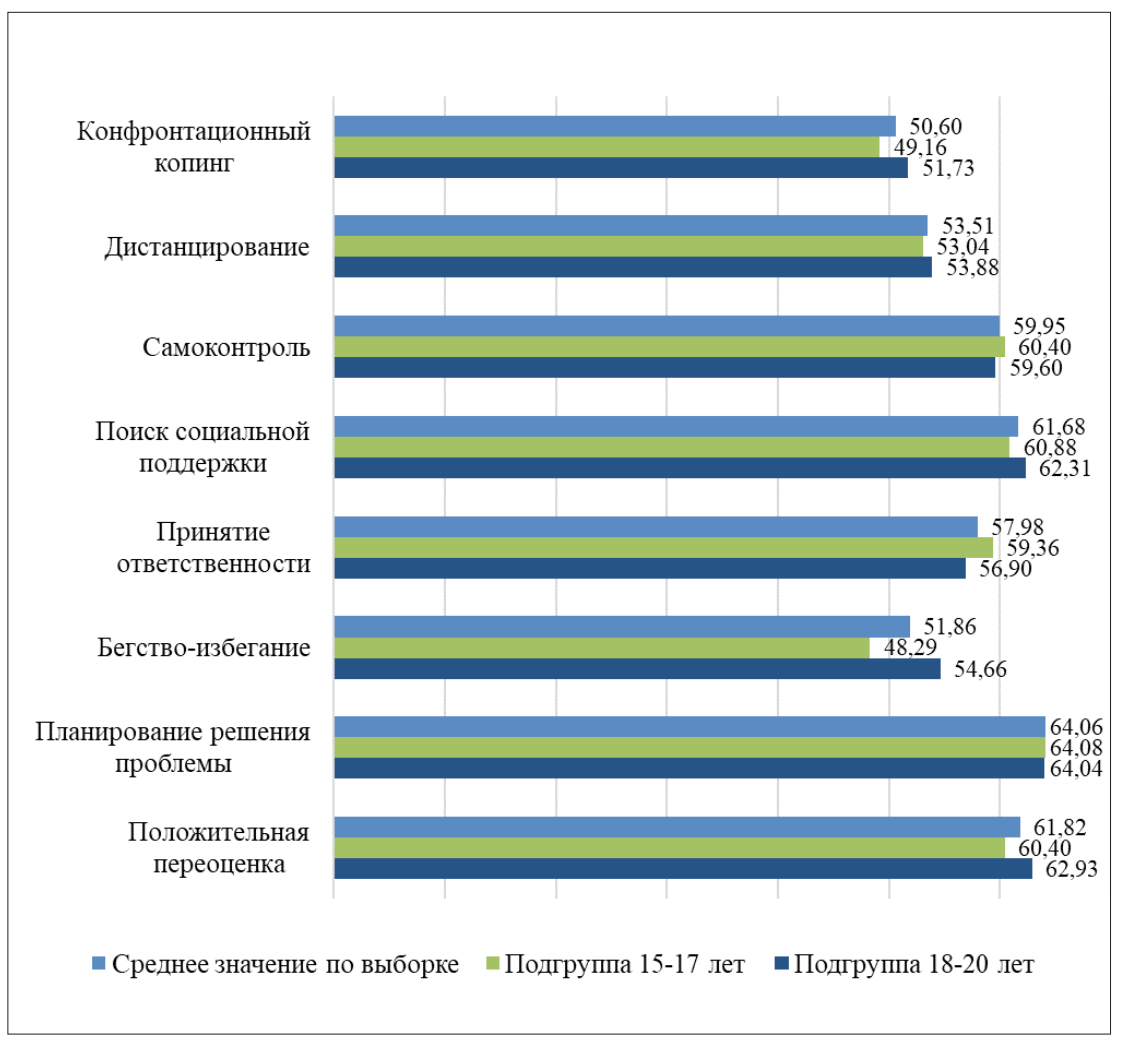

Рисунок 4. Средние значения показателей способов совладания (возраст).

Приведенные данные свидетельствуют о том, что в подгруппах 15-17 дет и 18-20 лет ведущие стратегии совладания (планирование решения проблемы, поиск социальной поддержки и положительная переоценка) выражены примерно в равной степени. Данные статистического анализа свидетельствуют о том, что достоверные раздичия отмечаются дишь по шкале способов совладания «Бегство-избегание» $(\mathrm{p}<0,05)$. Установлено, что подростки 18-20 лет чаще используют такой способ совладания, как избегание.

Сравнительный анализ средних значений по стилям саморегуляции приведен на рисунке 5 . 
Инновационная наука: психология. педагогика. дефектология 2021 TOM 4 № 5

ВОЗРАСТНАЯ ПСИХОЛОГИЯ

68 
По компонентам волевой регуляции, так же показано, что в подгруппе подростков 15-17 лет значения выше, в сравнении с подгруппой 18-20 лет. Общий уровень саморегуляции, и общий показатель волевой саморегуляции выше в подгруппе 15-17 лет.

Так, по показателям саморегуляции, в целом установлено, что в подгруппе подростков 18-20 лет достоверно преобладает стиль саморегуляции «Самостоятельность», то есть, подростки в возрасте 18-20 лет более автономны, менее зависимы от мнений и оценок окружающих, и менее склонны игнорировать проблему.

Далее был проведен анализ связей между стратегиями совладания и показателями саморегуляции в подгруппах, выделенных по возрасту. Результаты корреляционного анализа представлены на рисунке 7.

\section{Подгруппа 15-17 лет}

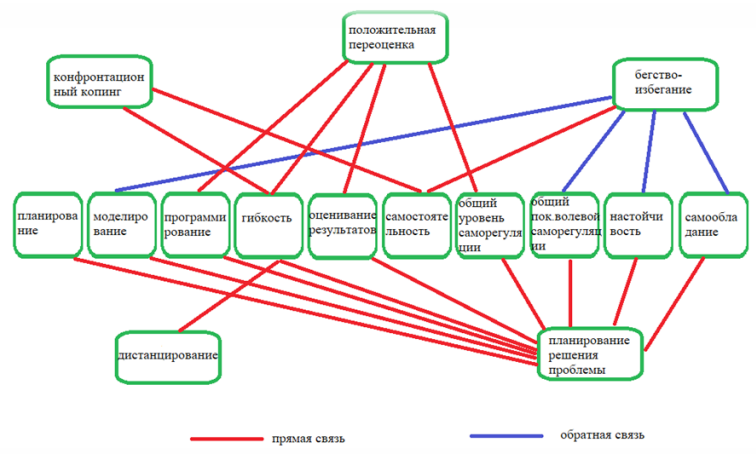

Подгруппа 18-20 лет

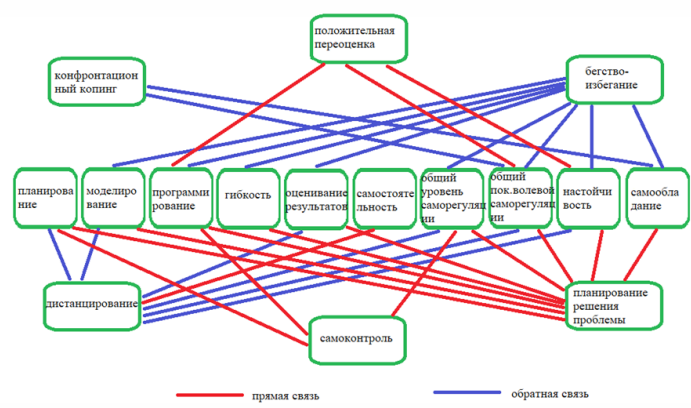

Рисунок 7. Корреляционный анализ стратегий совлаАания с показателями саморегуляции в полгруппах, вылеленных по возрасту. 
ВОЗРАСТНАЯ ПСИХОЯОГИЯ

По результатам корреляционного анадиза можно закдючить, что предпочтение тех или иных стратегий саморегуляции достоверно коррелирует с особенностями саморегуляции в подростковом возрасте. Однако были выявлены существенные раздичия в характере связей в раздичных возрастных группах. Так, стратегия конфронтации в младшей группе имеет положительные связи с гибкостью (Rs = 0,424 при p<0,001) и самостоятельностью (Rs = 0,380 при $\mathrm{p}<0,001)$, в то время как в старшей подгруппе - отрицательные с самообладанием $(\mathrm{Rs}=-0,354$ при $\mathrm{p}<0,001)$ и общим уровнем волевой регуляции ( $\mathrm{Rs}=-0,245$ при $\mathrm{p}<0,018)$. Следовательно, стратегия разрешения проблемы за счет поведенческой активности, направленной на ситуацию, либо на отреагирование негативных эмоций, на фоне возрастной динамики имеет раздичные механизмы. В возрасте 15-17 лет выбор данной стратегии опирается на ощущение уверенности и способность перестроиться в случае рассогласования полученных результатов с целью. При этом в старшей подгруппе реализация конфронтации уже в большей степени является импульсивным отреагированием негативных эмоций на фоне более низких показателей саморегуляции.

Положительная переоценка сохраняет связь с программированием в исследуемых подгруппах (в младшей Rs = 0,280 при p<0,017; в старшей Rs =0,325 при $\mathrm{p}<0,001)$. Однако в младшей группе также выражены связи с гибкостью $(R s=0,360$ при $p<0,002)$, оцениванием результатов ( $R s=0,302$ при $p<0,009)$ и общим уровнем саморегуляции ( $R s=0,331$ при $p<0,004)$, а в старшей с настойчивостью (Rs = 0,251 при $\mathrm{p}<0,015)$ и общим уровнем волевой саморегуляции ( Rs = 0,205 при p<0,049). Следовательно, в младшей подгруппе предпочтение стратегии положительного переосмысления ситуации и поиска позитивных сторон сопряжено со способностью продумывать и быстро перестраивать свои планы, а также с адекватностью оценки себя и результатов своего поведения. В то время как в старшей группе эта же стратегия больше связана со способностью продумывать план действий и придерживаться этого плана. Учитывая, что напряженность данной стратегии в исследуемых подгруппах завышена, а настойчивость в отсутствии связи с гибкостью может привести к ригидности и неэффективности поведения, можно предположить, что реадизация данной стратегии в старшей группе будет более дезадаптивна.

Стратегия бегство-избегание старшей подгруппе имеет большее количество отрицательных связей с показателями саморегуляции. В младшей группе бегствоизбегание имеет прямую связь с самостоятельностью (Rs = 0,293 при p<0,012), и обратные связи со шкалами: моделирование ( $\mathrm{Rs}=-0,333$ при $\mathrm{p}<0,004)$, общим показателем волевой саморегуляции (Rs $=-0,361$ при $\mathrm{p}<0,002)$, настойчивость (Rs $=-0,337$ при $\mathrm{p}<0,004)$, самообладание (Rs $=-0,253$ при $\mathrm{p}<0,031)$. В старшей с моделированием (Rs $=-0,507$ при $\mathrm{p}<0,001)$, программированием (Rs $=-0,224$ при $\mathrm{p}<0,031)$, оцениванием результатов ( $R s=-0,352$ при $\mathrm{p}<0,001)$, гибкость ( $R s=-0,313$ 
при $\mathrm{p}<0,002)$, общим уровнем саморегуляции ( $R s=-0,396$ при $\mathrm{p}<0,001)$, общим показателем волевой саморегуляции ( $\mathrm{Rs}=-0,614$ при $\mathrm{p}<0,001)$, настойчивостью $(R s=-0,555$ при $\mathrm{p}<0,001)$ и самообладанием (Rs $=-0,626$ при $\mathrm{p}<0,001)$. То есть, у старшей группы более выражена связь уровня саморегуляции и отдельных его стилей с предпочтением данной стратегии, а также с адаптивностью ее использования. Исходя из того, что старшая группа имеет более высокие показатели по этой стратегии и высокие (относительно норматива) показатели волевой регуляции, можно предположить, что в период 18-20 лет подростки при высоком уровне рефлексии личных мотивов и умении распределять усилия и контродировать свои поступки будут реже предпочитать неконструктивные формы поведения по типу отрицания или уклонения в стрессовых ситуациях.

У стратегии дистанцирования существенно меняется характер связей с особенностями саморегуляции. В возрасте 15-17 лет выбор стратегии отстранения (обесценивания или снижения значимости проблемы) опирается на гибкость регуляторных процессов ( $R s=0,252$ при $\mathrm{p}<0,032)$. В то время как, в возрасте 18-20 иет связь с гибкостью не выявлена, но обнаружена положительная связь с самостоятельностью (Rs = 0,216 при p<0,038) и ряд отрицательных связей со стилями саморегуляции планирование ( $\mathrm{Rs}=-0,281$ при $\mathrm{p}<0,001)$, моделирование $(R s=-0,330$ при $\mathrm{p}<0,006)$ и оценивание результатов ( $R s=-0,218$ при $\mathrm{p}<0,036)$, а также настойчивостью (Rs $=-0,236$ при $\mathrm{p}<0,023)$ и общими показателями саморегуляции ( $R s=-0,293$ при $\mathrm{p}<0,004)$ и волевой саморегуляции ( $R s=-0,211$ при $\mathrm{p}<0,042)$. Описанные данные позволяют предположить, что предпочтение стратегии обесценивания в старшей группе связано с низким уровнем развития саморегуляции, и чем более низкий уровень саморегуляции, тем более выражен будет дезадаптивный характер данного копинга.

Способ совладания «самоконтроль» не имеет связей в группе подростков 15-17 лет, тогда как в старшей группе выражены положительные связи с планированием (Rs = 0,233 при p<0,024), программированием (Rs =0,223 при $\mathrm{p}<0,032)$ и общим уровнем саморегуляции ( $\mathrm{Rs}=0,233$ при $\mathrm{p}<0,025)$. То есть, связь преодоления негативных переживаний за счет подавления эмоций с уровнем саморегуляции проявляется только в более зрелом возрасте. Учитывая, что данная стратегия одинаково выражена в исследуемых возрастных группах, это свидетельствует о раздичии в механизмах ее реализации. В старшей подгруппе предпочтение данной стратегии опирается на навыки саморегуляции и рационального планирования. В более младшей группе, вероятно, подавление эмоций имеет менее осознанный характер и опирается на другие личностные характеристики (например, тревожность и алекситимию), или, возможно, на особенности Я-концепции.

Стратегия планирование решения проблемы является преобладающей, как в старшей, так и в младшей группах, и сохраняет связь практически со всеми 
ВОЗРАСТНАЯ ПСИХОЯОГИЯ

показателями саморегуляции. В младшей группе планирование решения проблемы положительно коррелирует со шкалами планирование ( $\mathrm{Rs}=0,272$ при $\mathrm{p}<0,020$ ), моделирование ( $\mathrm{Rs}=0,327$ при $\mathrm{p}<0,005)$, программирование ( $\mathrm{Rs}=0,380$ при $\mathrm{p}<0,001)$, оценивание результатов ( $R s=0,353$ при $\mathrm{p}<0,002)$, гибкость ( $\mathrm{Rs}=0,492$ при $\mathrm{p}<0,001)$, общий уровень саморегуляции ( $\mathrm{Rs}=0,541$ при $\mathrm{p}<0,001)$, общий показатель волевой саморегуляции (Rs $=0,473$ при $\mathrm{p}<0,001)$, настойчивость (Rs = $0,476$ при $p<0,001)$ и самообладание (Rs = 0,384 при p<0,001). В старшей - с планированием (Rs =0,336 при $\mathrm{p}<0,001)$, моделированием ( $R s=0,282$ при $\mathrm{p}<0,006)$, программированием (Rs = 0,464 при $\mathrm{p}<0,001)$, оцениванием результатов $(\mathrm{Rs}=$ 0,273 при $\mathrm{p}<0,008)$, гибкостью (Rs = 0,261 при $\mathrm{p}<0,011)$, общим уровнем саморегуляции (Rs = 0,481 при p<0,001), общим показателем волевой саморегуляции $(\mathrm{Rs}=0,268$ при $\mathrm{p}<0,009)$, настойчивостью $(\mathrm{Rs}=0,276$ при $\mathrm{p}<0,007)$ и самообладанием (Rs = 0,245 при p<0,018). Данная стратегия по выборке в целом имеет высокий уровень напряженности, что может свидетедьствовать о неадекватном ее применении. Однако исходя из связи с положитедьными аспектами саморегуляции, преодоление трудностей посредством целенаправленного анадиза ситуации и планирования собственных действий с учетом прошлого опыта и имеющихся ресурсов, можно назвать наиболее эффективной стратегией в подростковом возрасте.

\section{Обсуждение резудьтатов}

Полученные данные о преобладании у подростков копинга в форме планирования решения проблемы, положительной переоценки и поиска социальной поддержки, в целом, согласуются с данными современных исследований, проведенных на сходных выборках (Нижегородцева, Тарасова, 2017; Хазова, Останина, 2014). Данные о преобладании программирования, оценивания результатов и гибкости как стилей саморегуляции, также находят подтверждение в дитературе (Нижегородцева, Тарасова, 2017). Однако в некоторых работах также обнаруживается преобладание стратегии совладания бегство-избегание в подростковом возрасте (Wang et al., 2021).

В отношении раздичий, обнаруженных в подгруппах юношей и девушек, в первую очередь, стоит отметить небольшое количество значимых раздичий по исследуемым показателям, что может быть связано со сравнительно небольшим количеством юношей в выборке. Однако более высокие значения по шкале бегства-избегания у юношей также отмечаются в работах современных ученых (Perzow, Bray, Wadsworth, Young, Hankin, 2021).

Исследования особенностей взаимосвязи показателей саморегуляции и копинг поведения широко представлены в современной научной дитературе (Бубновская, 2021; Захарова, Комарова, Карнеев, Карнеева, 2019; Нижегородцева, Тарасова, 2017; Хазова, Останина, 2014). В большинстве из них исследователями получены 
Innovative Science: psychology. pedagogy. defectology 2021 VOL. 4 \# 5

ВОЗРАСТНАЯ ПСИХОЯОГИЯ 
ВОЗРАСТНАЯ ПСИХОЛОГИЯ

\section{Питература}

Акименко, А. К. (2016). Взаимосвязь стратегий совладающего поведения и социально-психологических характеристик личности. Известия Саратовского университета. Новая серия. Серия Акмеология образования. Психология развития, 5(2), 151-157. doi: https://doi.org/10.18500/2304-9790-2016-5-2-151-156

Аптикиева, А. Р. (2019). Психолого-педагогический аспект преодоления стрессовых ситуаций в подростковом возрасте. Вестник Оренбургского государственного университета, 2(220), 6-14. doi: https://doi.org/10.25198/1814-6457-220-6

Бартош, О. П., Бартош, Т. П. (2012). Возрастные и гендерные особенности копинг-поведения подростков. Психология. Психофизиология, 6(265), 42-46.

Бубновская, О. В. (2021). Влияние саморегуляции на совладание и психологическую безопасность студенчества. Психология саморегуляици в контексте актуальных задач образования ( $\kappa$ 90-летию со дня рождения О.А. Конопкина), 1, 150-156. doi: https://doi.org/10.24412/cl-36466-2021-1-150-156

Быкова, Е. А. (2021). К вопросу о формировании волевых качеств в подростковом возрасте. Вестник Шадринского государственного педагогического университета, 2(50), 202-208.

Вассерман, Л. И. (2009). Методика для психологической диагностики способов совладания со стрессовыми и проблемныли для личности ситуацияли. Пособие для врачей и медицинских психологов. СПб.: Санкт-Петербургский научно-исследовательский психоневрологический институт им. В.М. Бехтерева.

Вассерман, А. И., Абабков, В. А., Трифонова, Е. А. (2010). Совладание со стрессом: теория и психодиагностика. Учебно-методическое пособие. СПб.: Речь.

Ветрова, И. И. (2008). Связь совладающего поведения с контролем поведения и психологической защитой в системе саморегуляции. Совладающее поведение: современное состояние и перспективы. Институт психологии РАН, 179-196.

Галузо, П. Р. (2021). Осознанная саморегуляция рискованного поведения современных подростков. Новая психология профессионального труда педагога: от нестабильной реальности к устойчивому развитию, 1, 298-301. doi: https://doi. org/10.24412/cl-36422-2021-1-298-301

Жукова, Е. С., Богоявленская, Д. Б., Артеменков, С. А. (2021). Соотношение одаренности, интеллекта, академической успешности и осознанной саморегуляции учебной деятельности. Психология саморегуляции в контексте актуальных задач образования (к 90-летию со дня рождения О.А. Конопкина), 1, 63-69. doi: https:// doi.org/10.24412/cl-36466-2021-1-63-69

Захарова, М. В., Комарова, С. В., Карнеев, Р. К., Карнеева, О. А. (2019). Особенности волевой саморегуляции и копинг-стратегий подростков на разных этапах спортивного дополнительного образования. Ученые записки университета имени П.Ф. Аесгафта, 9(175), 369-373. 
Innovative Science: psychology. pedagogy. defectology 2021 VOL. 4 \# 5

ВОЗРАСТНАЯ ПСИХОЯОГИЯ 
Folkman, S., Lasarus, R., Dunkel-Schetter, C., DeLongis, A., Gruen, R. J. (1986). Dynamics of a stressful encounter: Cognitive appraisal, coping and encounter outcomes. Journal of Personality and Social Psychology, 50(5), 992-1003. doi: https://doi. org/10.1037/0022-3514.50.5.992

Frydenberg, E. (1997). Adolescent Coping. Theoretical and Research Perspectives. London: Ruothledge.

Perzow, S., Bray, B., Wadsworth, M., Young, J., Hankin, B. (2021). Individual Differences in Adolescent Coping: Comparing a Community Sample and a Low-SES Sample to Understand Coping in Context. Journal of Youth and Adolescence, 50(4), 693-710. doi: https://doi.org/10.1007/s10964-021-01398-Z

Wang, M., Del Toro, J., Scanlon, C., Schall, J., Zhang, A., Belmont, A., Voltin, S., Plevniak, K. (2021). The roles of stress, coping, and parental support in adolescent psychological well-being in the context of COVID-19: A daily-diary study. Journal of Affective Disorders, 294, 245-253.

Zimmer-Gembeck, M. J. (2021). Coping flexibility: Variability, fit and associations with efficacy, emotion regulation, decentering and responses to stress. Stress and Health, 37(5), 848-861. doi: https://doi.org/10.1002/smi.3043

\section{References}

Akimenko, A. K. (2016). The Relationship between Coping Strategies and Social and Psychological Personal Characteristics. Proceedings of the Saratov University. Series: Acmeology of Education. Developmental Psychology, 5(2), 151-157. doi: https:/l doi.org/10.18500/2304-9790-2016-5-2-151-156 (in Russ.)

Aptikieva, L. R. (2019). Psycho-pedagogical aspect of overcoming stressful situations in adolescence. Journal of the Orenburg State University, 2(220), 6-14. doi: https://doi.org/10.25198/1814-6457-220-6 (in Russ.)

Bartosh, O. P., Bartosh, T. P. (2012). Age and gender features of coping behavior of adolescents. Psychology. Psychophysiology, 6(265), 42-46. (in Russ.)

Bubnovskaia, O. V. (2021). Impact of self-regulationon coping and psychological safety of students. Psychology of self-regulation in the context of actual problems of education (to the 90th anniversary of the birth of O.A. Konopkin), 1, 150-156. doi: https:// doi.org/10.24412/cl-36466-2021-1-150-156 (in Russ.)

Bykova, E. A. (2021). To the question of the formation of strong-willed qualities in adolescence. Journal of the Shadrinsky State Pedagogical University, 2(50), 202-208. (in Russ.)

Dias, P. C. (2017). Protective factors and resilience in adolescents: The mediating role of self-regulation. Psicologia Educativa, 23(1), 37-43. doi: https://doi.org/10.1016/j. pse.2016.09.003

Feldstein, D. I. (2005). Psychology of human development as a person. Selected works in 2 vol. Moscow: Publishing house of the Moscow Psychological and Social Institute. (in Russ.) 
Filatova, A. F. (2009). Gender differences in the formation of a teenager's character: concept, experiment, practice. Monograph. Omsk: Sphere. (in Russ.)

Folkman, S., Lasarus, R., Dunkel-Schetter, C., DeLongis, A., Gruen, R. J. (1986). Dynamics of a stressful encounter: Cognitive appraisal, coping and encounter outcomes. Journal of Personality and Social Psychology, 50(5), 992-1003. https://doi. org/10.1037/0022-3514.50.5.992

Frydenberg, E. (1997). Adolescent Coping. Theoretical and Research Perspectives. London: Ruothledge.

Galuzo, P. R. (2021). Conscious self-regulation of risky behavior of modern teenagers. New psychology of professional work of a teacher: from unstable reality to sustainable development, 1, 298-301. doi: https://doi.org/10.24412/cl-36422-2021-1-298-301(in Russ.)

Hazova, S. A., Ostanina, N. V. (2014). Agespecific of Coping Behavior of adolescents. Siberian Pedagogical Journal, 1, 180-185. (in Russ.)

Kazakova, I. V. (2021). Regulation of internal Activity as a Factor of Coping with Difficult Life Situations. Psychopedagogy in law enforcement agencies, 26(1(84)), 48-52. (in Russ.)

Khasanyanova, A. A., Baryshnikova, E. V. (2021). Theoretical foundations of emotional stability of older adolescents. New impulses of development: Issues of Scientific Research, 1, 240-243. (in Russ.)

Kryukova, T. L. (2005). Age and cross-cultural differences in coping strategies of personality behavior. Psychological Journal, 26(2), 5-15. (in Russ.)

Kryukova, T. L. (2008). A person as a subject of coping behavior. Psychological Journal, 29(2), 88-95. (in Russ.)

Lazarus, R. (1970). Theory of stress and psychophysiological research. Emotional stress. M.: Nauka. (in Russ.)

Levchenko, V. O. (2009). Effect of controlling strategies upon adolescents' personality success. Science. Innovation. Technologies, 2, 187-192. (in Russ.)

Morosanova, V. I. (2010). Individual features of conscious self-regulation of voluntary human activity. Journal of the Moscow University. Series 14: Psychology, 1, 36-45. (in Russ.)

Nartova-Bochaver, S. K. (1997) «Coping behavior» in the system of concepts of personality psychology. Psychological Journal, 18(5), 20-30. (in Russ.)

Nikolaeva, A. A., Savchenko, I. A., Pavlova, T. S. (2019). Coping behavior of teenagers. Educational resources and technologies, 2(27), 33-39. (in Russ.)

Nizhegorodtseva, N. V., Tarasova, S. S. (2017). Features of Coping Behaviour of Adolescents with Different Levels of Conscious Self-Regulation. Journal of Yaroslavl Pedagogical, 2, 211-215. (in Russ.)

Ovcharova, R. V. (2020). The relationship between the manifestations of laziness and conflict of self-regulation among adolescents. Society: Sociology, Psychology, Pedagogy, 4, 76-80. (in Russ.) 
ВОЗРАСТНАЯ ПСИХОЛОГИЯ

Panina, E. V. (2011). The study of sexual characteristics of self-regulation in adolescents. Journal of Cherepovets State University, 4(1(33)), 132-136. (in Russ.)

Papsheva, L. V. (2013). Stylistic Peculiarities of Personality Behavior Self-regulation in Late Adolescence. Journal of the Saratov University. Series: Acmeology of Education. Developmental Psychology, 2(1), 41-47. (in Russ.)

Perzow, S., Bray, B., Wadsworth, M., Young, J., Hankin, B. (2021). Individual Differences in Adolescent Coping: Comparing a Community Sample and a Low-SES Sample to Understand Coping in Context. Journal of Youth and Adolescence, 50(4), 693-710. doi: https://doi.org/10.1007/s10964-021-01398-z

Vetrova, I. I. (2008). The relationship of coping behavior with behavior control and psychological protection in the system of self-regulation. Coping behavior: current state and prospects. Institute of Psychology of the RAS, 179-196. (in Russ.)

Wang, M., Del Toro, J., Scanlon, C., Schall, J., Zhang, A., Belmont, A., Voltin, S., Plevniak, K. (2021). The roles of stress, coping, and parental support in adolescent psychological well-being in the context of COVID-19: A daily-diary study. Journal of Affective Disorders, 294, 245-253.

Wasserman, L. I. (2009). Methodology for psychological diagnostics of coping methods with stressful and problematic situations for the individual. Manual for doctors and medical psychologists. St. Petersburg: St. Petersburg Research Psychoneurological Institute named after V. M. Bekhterev. (in Russ.)

Wasserman, L. I., Ababkov, V. A., Trifonova, E. A. (2010). Coping with stress: theory and psychodiagnostics. Educational and methodical manual. St. Petersburg: Rech'. (in Russ.)

Zakharova, M. V., Komarova, S. V., Karneev, R. K., Karneeva, O. A. (2019). Features of strong-willed self-regulation and coping strategies of teenagers at different stages of sports additional education. Scientific Notes of the P.F. Lesgaft University, 9(175), 369-373. (in Russ.)

Zhukova, E. S., Bogoyavlenskaya, D. B., Artemenkov, S. L. (2021). The ratio of giftedness, intelligence, academic success and conscious self-regulation of learning activities. Psychology of self-regulation in the context of actual problems of education (to the 90th anniversary of the birth of O.A. Konopkin), 1, 63-69. doi: https://doi.org/10.24412/ cl-36466-2021-1-63-69 (in Russ.)

Zimmer-Gembeck, M. J. (2021). Coping flexibility: Variability, fit and associations with efficacy, emotion regulation, decentering and responses to stress. Stress and Health, 37(5), 848-861. doi: https://doi.org/10.1002/smi.3043 